\title{
Dejar el crudo en tierra o la búsqueda del paraíso perdido. Elementos para una propuesta política y económica para la Iniciativa de no explotación del crudo del ITT ${ }^{1}$
}

\author{
Alberto Acosta* \\ Eduardo Gudynas** \\ Esperanza Martínez ${ }^{* * *}$ \\ Joseph Vogel $^{* * * *}$
}

“Todos colaboramos para un mismo resultado, unos consciente y consecuentemente, otros sin saberlo, como los que duermen, creo, de quienes Heráclito dice que son operarios y colaboradores de lo que sucede en el universo. Cada uno colabora en cosa distinta, sobre todo el que se queja e intenta contravenir y eliminar lo que sucede: pues también de gente tal precisa el universo. Queda entonces que pienses en qué filas quieres formar tú.”

Marco Aurelio, emperador romano (121-180)

Resumen: El documento presenta la propuesta ecuatoriana como una política pública viable tanto desde el punto de vista nacional como internacional. Se

\footnotetext{
${ }^{1}$ En este artículo se presentan opiniones personales que no comprometen a las instituciones donde los autores desarrollan sus actividades.

*FLACSO-Ecuador, Quito, Ecuador. Email: alacosta48@yahoo.com

** Centro Latino Americano de Ecología Social (CLAES), Montevideo, Uruguay. Email: egudynas@gmail.com

*** Oilwatch y Acción Ecológica, Quito, Ecuador. Email: tegantai@oilwatch.org

${ }^{* * * *}$ Universidad de San Juan de Puerto Rico-Río Piedras, Puerto Rico. Email: josephvogel@hotmail.com; josephvogel@usa.net
} 
analizan las razones de por qué no debe atarse esta iniciativa al mercado de carbono, y se proponen premisas para impulsar acuerdos políticos que tendrán como momento clave la reunión del Convenio de Cambio Climático en Copenhague. En el documento se proponen varias posibilidades y condiciones políticas y económicas para estructurar un fondo solidario a fin de hacer viable la iniciativa de no explotación del crudo en el Parque Nacional Yasuní. Se destaca que la propuesta ha recibido ya el respaldo del Parlamente Alemán, y que está en la agenda de varios parlamentos y gobiernos a nivel internacional.

Palabras clave: Yasuní, Copenhague, mercado de carbono, ITT

\title{
Leave crude oil in the ground or the search for paradise lost. Elements for a political and economic proposal to the Initiative of non exploitation of crude oil of the ITT
}

\begin{abstract}
The document presents the Ecuadorian proposal as a viable public policy from both national and international perspectives. It discusses the reasons why this initiative should not be tied to the carbon market, and proposes premises in order to pursue political agreements that will have their key moment the meeting for the Convention on Climate Change in Copenhagen. The document suggests several potential political and economic conditions in order to structure a solidarity fund to make the viable the initiative of non-exploitation of crude oil in Yasuni National Park. It stands out that the proposal has already received the backing of the German Parliament, and that it is on the agenda of several governments and parliaments at international level.
\end{abstract}

Key words: Yasuní, Copenhagen, carbon market, ITT

Recibido: 14.05.2009

Aprobado: 01.07.2009

$* * *$

\section{Introducción}

En el año 2007, el Ministerio de Energía y Minas de Ecuador, presentó públicamente la propuesta de no explotar el petróleo en la zona del Parque Nacional Yasuní. La iniciativa representaba una acción sustantiva para la protección ambiental del área y sus habitantes, y para innovar en la búsqueda de alternativas al desarrollo extractivista tradicional basado en la exportación de productos primarios. La propuesta, también conocida como iniciativa ITT (en referencia a las reservas petroleras del corredor IshpingoTambococha-Tiputini, ubicado en ese parque), rápidamente motivó una importante atención a nivel internacional, y un prolífico debate sobre las vías que debían transitarse para concretarla. Asimismo, se entendía que esa medida implicaría contar con recursos financieros, y por lo tanto también se debatían los medios para concretar ese mecanismo.

La iniciativa encierra múltiples aspectos, tales como constituirse en un punto de ruptura en la historia ambiental del país o poder convertirse en 
una medida emblemática para enfrentar en la práctica el calentamiento global, superando la etapa de los discursos sin propuestas efectivas. Es un paso vigoroso para cuestionar la lógica del desarrollo extractivista (primario-exportador) y, simultáneamente, es una opción para construir globalmente el Buen Vivir. El proyecto, en concreto, se sustenta en una visión respetuosa de la Naturaleza y de las opciones culturales de los pueblos originarios en aislamiento voluntario que todavía habitan el territorio ecuatoriano.

Por cierto que la presentación de esta Iniciativa en 2007, en tanto sintetiza un camino alterno al modelo de desarrollo basado en las exportaciones primarias, suscitó polémicas. Sin embargo, la crisis económica de 2008 dejó en evidencia las serias contradicciones de ese estilo de desarrollo, la fragilidad que encierra para economías como la ecuatoriana, y la necesidad de comenzar a buscar caminos alternativos. En efecto, la propuesta ITT permitiría abrir las puertas a la construcción colectiva de una economía post-petrolera, continuando con una tarea que empezó en Ecuador hace muchos años.

La Iniciativa ITT apunta a evitar la explotación de combustibles fósiles en áreas de alta sensibilidad biológica y cultural. Por lo tanto, es una medida para proteger la biodiversidad en la Amazonía, y los procesos ecológicos que ella sustenta. A su vez, también se busca aprovechar el nuevo contexto internacional, donde se debaten nuevos compromisos sobre energía y ambiente, lo que ofrece la posibilidad de consolidar un liderazgo político de Ecuador a nivel mundial.

Han transcurrido más de dos años desde la presentación pública de esta Iniciativa, y los medios e instrumentos para concretarla todavía no han sido clarificados ni consensuados. Ante esta situación, entendemos que es indispensable contribuir a ella desde la reflexión y el análisis. Este texto recoge un ejercicio ciudadano en el que varias personas, quienes no necesariamente están de acuerdo en todo, coinciden en discutir un tema y proponer una serie de ideas más o menos consensuadas con el fin de incentivar al debate.

Este documento colectivo es en sí mismo una buena práctica para demostrar que es posible una gestión ambiental basada en la pluralidad de valoraciones. En ese sentido, en este documento se postula que la Iniciativa ITT cuenta con sólidos argumentos para ser defendida, en atención a la protección de los grupos humanos del área, de la relevancia ecológica por su alta biodiversidad, el aporte a mitigar el cambio climático global, y el ejemplo de una senda posible para un desarrollo postmaterial que libere al país de la dependencia de los sectores extractivos. Consideramos que la Constitución de la república del Ecuador, del año 2008, refuerza la importancia de la Iniciativa, en especial los mandatos ambientales y del Buen Vivir. Consecuentemente, entendemos que la Iniciativa ITT debe ser abordada como una política pública, donde es necesario dejar en claro sus contenidos políticos. 
El sustento de esa Iniciativa requiere un componente económicofinanciero. En este documento se analizan diversos aspectos en ese campo. No obstante, la concreción de esos componentes no puede ser usada como excusa para la inacción. En realidad se dispone de varias opciones, que responden a distintas concepciones sobre el sentido del aporte económico. Por lo tanto, existe más de un camino para recorrer en la búsqueda de aportes económicos, que deben ser entendidos como coadyuvantes a la Iniciativa, pero no como su condición esencial de posibilidad. Finalmente, postulamos que el diseño de esos mecanismos y la defensa de la Iniciativa, requieren un nuevo y mayor protagonismo del gobierno ecuatoriano a nivel internacional, tanto a nivel regional (con los demás países amazónicos) como a nivel internacional.

\section{La iniciativa ITT: presentación y estado del debate}

Las reservas del ITT están ubicadas en el sector nororiental del Parque Yasuní. Las últimas estimaciones del yacimiento son de 846 millones de barriles recuperables de crudos pesados (14,7 $\mathrm{API})$. Estas se explotarían alrededor de 13 años, a razón de 107.000 barriles diarios, desde el quinto año. La extracción del crudo es parte de un paquete que también incluye la refinación y una planta de generación termoeléctrica. El Parque Yasuní, fue creado en 1979, sufriendo varios cambios en sus límites y superficie, y en la actualidad cubre 982 mil hectáreas (Fontaine y Narváez, 2007). En la actualidad, la situación actual del parque es mala ya que, entre las áreas protegidas de Ecuador, es el que posee la menor inversión de dinero en relación a su superficie, y cuenta con el equipo humano más reducido (Fontaine, 2007).

A partir de su primera formulación pública, la Iniciativa ITT ha recibido mensajes de aliento y también varios comentarios caracterizados por la duda y la incomprensión. Al mediar el año 2008, se logró uno de los mayores espaldarazos con el apoyo formal del Parlamento Alemán, que recomendó a otros parlamentos europeos asumir un respaldo similar. El gobierno alemán concretó ya un aporte financiero para cristalizar la propuesta. Aun cuando no se logró hacer realidad el apoyo del gobierno noruego, que financia el mayor fondo Europeo para reducción de emisiones por deforestación y degradación, varios sectores políticos y de la sociedad de ese país están también interesados en apoyar para la propuesta ecuatoriana. La Iniciativa también ha sido recibida con entusiasmo por parte de miembros del Parlamento Europeo, al igual que por instituciones parlamentarias norteamericanas, algunos organismos multilaterales y varias organizaciones de la sociedad civil a nivel internacional. El entusiasmo que despertó internacionalmente contrasta con la todavía relativamente tibia acogida en el Ecuador, lo que se explica por las limitadas acciones de promoción dentro de este país.

El presidente de la República, Rafael Correa, presentó en 2007, en el seno de las Naciones Unidas, la idea de mantener bajo tierra las reservas de crudo pesado, si la comunidad internacional compensa al Ecuador con 
al menos la mitad de las rentas que recibiría por la explotación de ese crudo. En ese momento no se habían contemplado las múltiples dificultades involucradas en estimar cuánto sería dicho monto. Sin embargo, el mensaje apunta a una responsabilidad compartida entre el Ecuador y el extranjero.

La Iniciativa recibió (indirectamente) un respaldo político nacional el 28 de septiembre del 2008, cuando la sociedad ecuatoriana aprobó mayoritariamente la Constitución de la República redactada en Ciudad Alfaro, en Montecristi. Su eje central es el concepto del Buen Vivir o sumak kawsay y el reconocimiento de los Derechos de la Naturaleza. La Iniciativa ITT, como parte de esta nueva visión de desarrollo en Ecuador, está acompañada de otras propuestas del mismo presidente Correa. Por ejemplo, en el seno de la Organización de Países Exportadores de Petróleo (OPEP), en noviembre del 2008, se postuló la instauración de un impuesto sobre las exportaciones de petróleo para financiar la lucha contra la pobreza y la promoción de energías alternativas para contrarrestar el cambio climático. Asimismo, la propuesta de no pago de la deuda externa, que se presenta como resultado de la auditoría de la deuda, contribuye para reflexionar sobre la necesidad de cambiar profundamente las negociaciones internacionales y de avanzar en modelos de justicia global.

Lamentablemente el gobierno todavía no ha definido y propuesto públicamente aún una estrategia clara y definida, a pesar de las varias y cada vez más entusiastas presentaciones de la Iniciativa por parte del presidente Correa en el exterior. Atentan en contra de esta Iniciativa varias y repetidas posiciones inconsistentes y contradictorias del gobierno. Aunque la propuesta pueda parecer a momentos un nudo gordiano, cualquier ambigüedad pone en riesgo esta Iniciativa realmente revolucionaria.

Transcurridos más de dos años desde la formulación pública de esta Iniciativa todavía no están definidos los instrumentos que deberían cristalizarla. Por ejemplo, no está claro cuál será el mecanismo para asegurar el financiamiento requerido, ni los pasos políticos para encaminar con mayor claridad a la economía ecuatoriana a una etapa post-extractivista y para impulsar, a nivel internacional los pilares de lo que deberá ser una política internacional de convivencia basada en la justicia ambiental.

\section{Elementos claves en el marco conceptual de la iniciativa ITT}

En la presente sección se analizan y comentan algunos aspectos clave para el sustento conceptual de la Iniciativa ITT.

\section{El contexto generado por la nueva constitución}

La nueva Constitución de Ecuador retoma y cristaliza varias ideas, conceptos y demandas que están directamente vinculadas con el caso ITT. 
El nuevo texto constitucional genera un fuerte mandato por la justicia social y por la defensa de la Naturaleza. Esto se expresa, especialmente, en el reconocimiento de los Derechos de la Naturaleza, y en la directa vinculación de la protección de los recursos naturales con un régimen de desarrollo concebido como plural y orientado al Buen Vivir. Siguiendo esa línea, la iniciativa del ITT está claramente basada en la justicia ambiental y social. La protección del área, tal como se verá más abajo, responde a una evaluación sobre la relevancia de su riqueza ecológica, la importancia de sus comunidades humanas, y el alto costo social, ambiental y económico de ese tipo de emprendimientos.

Esta postura se desenvuelve bajo una pluralidad de valores como nuevo punto de partida para el diseño y discusión de políticas públicas, donde el análisis económico clásico, del tipo costo-beneficio basado en los valores de mercado, no puede ser el único sustento de una política pública. En especial, reconoce que la dimensión ambiental no se puede disociar de la social y que un sinnúmero de valores son incomensurables.

En concordancia con el nuevo texto constitucional, el enfoque del Buen Vivir debe basarse en los Derechos Humanos y los Derechos de la Naturaleza. Al reconocer la pluralidad de valores, tales como estéticos, religiosos, culturales, ambientales, etc., permite la incorporación de los derechos propios de la Naturaleza, tal como reconoce la Constitución ecuatoriana. Consecuentemente, esto lleva a abordar la toma de decisiones como un proceso político y no como una resolución técnica basada en el costo / beneficio. Asimismo, también se responde al desarrollo de responsabilidades comunes pero diferenciadas en relación a los cambios climáticos, a la conservación de la biodiversidad, al deterioro ambiental en general y a la crisis financiera global.

La Iniciativa también se fundamenta en la idea de una estrategia de desarrollo post-material, con un componente post-extractivo, desde la realidad de un país dependiente de las exportaciones petroleras, como lo es Ecuador. Esto exige diseñar propuestas de gestión innovadoras; es decir, cómo llevar a la práctica ideas revolucionarias, que requieren mecanismos imaginativos de financiamiento (y que se presentan más abajo) y cómo aprovechar de ideas, por muchos años rechazadas o marginadas, y sumamente pertinentes en la actualidad.

En definitiva, una propuesta innovadora como ésta requiere de herramientas también innovadoras. Son indispensables esfuerzos que nos obliguen a repensar las cosas imaginativamente, sin desconocer los avances de la economía y la política en este campo ambiental, pero reconociendo que estos avances deben enriquecerse permanentemente para poder enfrentar una realidad atravesada por múltiples factores, especialmente por ideas profundamente arraigadas que impiden superar las sombras del pasado. En el siguiente punto se discuten algunas de ellas. 


\section{Las fundamentaciones sobre la moratoria petrolera en el Yasuní}

A partir del nuevo contexto constitucional, es posible ordenar la fundamentación de la propuesta en al menos tres planos:

\section{a) Razones nacionales}

En el plano nacional, existen varios argumentos para fundamentar la decisión de mantener bajo tierra el petróleo de Yasuní. En primer lugar, evitaría la desaparición de las comunidades tagaeri, taromenane y oñamenane, que forman parte de la nacionalidad huaorani, cuya subsistencia se ha basado en la caza, recolección y agricultura itinerante. Los huaorani han sobrevivido el asedio de otras culturas y de la civilización occidental internándose en planicies interfluviales como las del Parque Yasuní. Sin embargo, la permanente y expansiva explotación de los bosques y la misma actividad petrolera han afectado irreversiblemente a la mayor parte de esa población. En concreto los tagaeiri, taromenane y oñamenane han optado por el aislamiento voluntario. Sobreviven en la zona intangible al sur del Parque Yasuní.

La importancia ambiental del área es indiscutible. Las reservas del ITT se encuentran bajo una de las áreas de mayor biodiversidad del planeta, que alberga no menos de 165 especies de mamíferos, 110 de anfibios, 72 de reptiles, 630 de aves, 1.130 de árboles y 280 de lianas, sin contar con innumerables especies de invertebrados todavía no estudiados (véase por ejemplo, GeoAmazonia, 2008).

La normativa nacional exige tanto la protección de los grupos humanos como la conservación de esos ecosistemas. Esto incluye las normas sobre derechos colectivos de los pueblos indígenas, las leyes y reglamentos nacionales sobre protección ambiental, áreas protegidas, pero sobre todo los Derechos de la Naturaleza. La actual Constitución refuerza y profundiza esos aspectos. La importancia del área es tal que la UNESCO la declaró Reserva Mundial de la Biosfera en 1989.

La situación actual es negativa. Se ha alertado que el "modelo de conservación en el Yasuní está al borde del colapso”, donde la responsabilidad del Estado en asegurar esa protección no se efectiviza, debido a tensiones, disputas, incertezas legales y bajo cumplimiento de la normativa, que generan y reproducen conflictos (Narváez, 2007 y 2009). Esa dinámica se debe en buena medida a las presiones y aspiraciones de explotación petrolera, de donde la Iniciativa ITT tiene el enorme valor en remover el principal factor de presión sobre el área. La apertura del parque a las empresas petroleras provocará el mismo proceso observado en otros sitios amazónico: contaminación, destrucción de las bases de subsistencia de las poblaciones locales. Después del ingreso de las empresas petroleras, vendrán otros actores, que van desde aquellos involucrados en la tala ilegal, incendios forestales o prácticas agrícolas ajenas a las características propias de una zona como ésta. Finalmente, entre las razones nacionales está 
claro que si se contabilizan los costos económicos de los impactos sociales, ambientales y productivos, de la extracción del petróleo, desaparecen muchos de los beneficios económicos potenciales (véase, por ejemplo, sobre los pasivos de la industria petrolera el aporte de Fander Falconí, 2004).

\section{b) Razones regionales}

El área de Yasuní es parte de la gran bioregión amazónica, que ocupan Ecuador junto a otros siete países (Brasil, Bolivia, Colombia, Perú, Venezuela, Guyana y Suriname) y un territorio (Guayana Francesa). Por lo tanto, su suerte, sea en su preservación como en su destrucción, está directamente relacionada con los ecosistemas de la selva tropical amazónica. En tanto parte de un conjunto de ecosistemas compartidos, Yasuní está vinculada a la biodiversidad regional, la dinámica del clima en la cuenca amazónica, sus ciclos hidrológicos, los corredores de fauna y flora que siguen las cuencas de los cursos de agua, etc.

En el ámbito de la Comunidad Andina, Ecuador junto a los demás países, aprobaron la "Estrategia Regional de Biodiversidad para los países del trópico andino" (Decisión 523, 7 julio 2002). Esta Estrategia, que impone diversas metas en conservación de la biodiversidad, todavía tiene varias limitaciones por su concepción mercantil, por lo tanto debe ser repensada antes de ser llevada adelante por las autoridades ambientales de cada país y de todos de manera consensuada. Ecuador puede tomar un papel líder a nivel regional, protegiendo la Amazonía e impulsando a los países de la región a medidas similares.

\section{c) Razones globales}

En este caso, el aporte clave se debe a que mantener el petróleo en tierra implicaría que se dejaran de quemar el crudo del ITT, y por lo tanto se estima que se evitaría la emisión de más de 400 millones de toneladas métricas de CO2. Asimismo, la pérdida de bosques es otra de las causas muy conocidas en generar gases con efecto invernadero. Por lo tanto, evitar la deforestación también reduce en forma directa las emisiones de gases. Estos argumentos remiten a los compromisos asumidos por el país a nivel internacional, en especial los de la Convención Marco en Cambio Climático, así como la Convención de la Diversidad Biológica.

\section{La iniciativa ITT como una política pública}

Entendemos que la relevancia del caso y el contexto constitucional desembocan en considerar que la Iniciativa ITT debe ser entendida como una política pública. Esto implica reconocerle el mismo rango que otros componentes clave, por ejemplo en la política de salud o de educación. La iniciativa no debería ser encasillada como específicamente ambiental, ya que como se discutió arriba aborda aspectos sustanciales en las dimensiones sociales y económicas. 
Aun cuando en el debate sobre desarrollado por el gobierno de Rafael Correa se pone el acento en una compensación por mantener el petróleo en tierra, la propuesta es esencialmente política y debe defenderse y desarrollarse en este ámbito. En la economía ortodoxa se contemplan la eficiencia y la equidad, pero generalmente esa se queda de segundo plano. La Iniciativa ITT muestra que se logrará la eficiencia por considerarse primero la equidad. Se trata de construir desde esta propuesta, un conjunto de acciones para un modelo que permita salir de la debilidad intrínseca del dólar, de la dependencia petrolera, y construir el Sumak Kawsay (Buen Vivir). Esta estrategia es esencialmente nacional; requiere un componente internacional, pero sus motivos y objetivos son nacionales. En definitiva se quiere colocar nuevas bases que construyan relaciones de justicia norte sur. Esto explica la razón por la cual el Sumak Kawsay es uno de los pilares es que sostiene la Iniciativa.

Desde el punto de vista político, la iniciativa podría ser calificada como ajena a la realidad, y por lo tanto ingenua o radical. Han existido expresiones en este sentido, y es oportuno abordarlas en un plano conceptual. A manera de ejemplo, se puede tomar la postura de Fontaine (2007) en tanto es una de las más elaboradas, y donde acuerda con nosotros en que lo que está en juego es una opción política, pero la entiende como una oposición entre un "ecologismo utópico" y una "política petrolera nacionalista”.

Sin embargo, la Iniciativa Yasuní no puede ser calificada como una forma de "ecologismo utópico". En primer lugar, el reclamo de protección del área si bien es parte de las demandas del ecologismo como movimiento ciudadano, también es un mandato para el propio Estado, emanado de su legislación actual y de su nueva Constitución, es decir del pueblo ecuatoriano. El calificativo de "utópico", en un sentido negativo como irrealizable o fantasioso no es oportuno, ya que la crisis del sector petrolero global es evidente, el camino hacia una creciente escasez del recurso es inevitable, así como los crecientes costos socioambientales en su extracción, y el cambio climático global. Por lo tanto, la postura "realista" es precisamente reconocer estos problemas, adelantarse a ellos, y buscar salidas productivas genuinas alternativas al petróleo. En cambio, el calificativo "utópico", si es tomado como un horizonte al cual se avanza, y se quiere trascender, como punto de quiebre para superar las limitaciones de la actual ideología del progreso, es por demás oportuno.

En segundo lugar, la oposición no es contra una "política petrolera nacionalista”. Por el contrario, la Iniciativa Yasuní recupera el control total sobre esos recursos, los deja en manos de Ecuador, y no enfrenta los riesgos de dependencia y subordinación a las empresas petroleras transnacionales. Asimismo, no hay mucho de nacionalismo en habilitar la contaminación del área o atentar contra los grupos indígenas.

A nuestro modo de ver, la Iniciativa Yasuní no es solo parte de una política ambiental nacional, sino que es un ingrediente para otra política energética nacional, donde no se excluye el sector petrolero, pero se lo 
coloca en otro contexto, apelando a fuentes de energía diversificadas y plurales (ver Acosta, 2009).

\section{Los límites de la Naturaleza}

Es oportuno ofrecer algunas consideraciones sobre los límites ecológicos. La Naturaleza tiene límites que la economía no debe ni puede sobrepasar. Estos se expresan a nivel local (como es la extinción de especies amazónicas, o la contaminación por crudo tal como atestiguan muchos casos, como las provocadas por la Chevron-Texaco en la Amazonía ecuatoriana, Berinstain et al. 2009); en el plano regional (por ejemplo, las alteraciones en la dinámica del clima amazónico y el régimen de lluvias); y a nivel global (donde el caso más conocido es el cambio climático, resultado del sobreconsumo energético).

El pensamiento convencional se limita a hacer de los bienes y servicios elementos transables, a través de la dotación de derechos de propiedad, pero no incorpora esa noción de límites. Sin embargo, se ha acumulado mucha información acerca de las consecuencias del sobre uso de los recursos naturales y las capacidades de los ecosistemas y el planeta de amortiguar los impactos. Esta es una situación que se produce debido a la generalización de un comportamiento egoísta, incapaz de reconocer que un recurso tiene un límite o umbral antes de colapsar.

\section{Algunas reflexiones económico-ecológicas}

\section{a) Los límites de la economía convencional}

El problema del deterioro ambiental en una economía de mercado es que no considera plenamente en sus cálculos los efectos externos, tiende a socavar los intereses de las futuras generaciones y los derechos de las otras especies. Todavía existe aun un gran desconocimiento del valor (que no es lo mismo que el precio), se ignora la pluralidad de valores y las complejas funciones de los ecosistemas y especies. En este contexto el análisis costo-beneficio no es aplicable, pues tiende a valorar en cero lo que se desconoce, o valora utilitariamente los recursos que pueden ser aprovechados, así como enfrenta problemas en determinar una tasa de descuento, o en decidir cuál es la escala de tiempo a considerar. Irónicamente, dicho análisis aplicado a un hotspot de biodiversidad es una de las amenazas más grandes que sufre la misma. Esta advertencia se ha hecho en Ecuador repetidas veces; por ejemplo, Fander Falconí sostenía en 2004 que algunos daños desencadenados por la actividad petrolera pueden ser mensurados económicamente, y por lo tanto compensables, pero otros son simplemente inconmensurables.

Finalmente, es cada vez más aceptada la noción de que introducir en 
el mercado dichos servicios significaría transferir al mercado asimétrico la responsabilidad de definir los aspectos distributivos asociados con sus usos. Esto puede generar un proceso de concentración en el acceso a estos recursos y de consiguiente pérdida de soberanía para las poblaciones usuarias de dichos ecosistemas.

\section{b) Límites y posibilidades de la compensación económica}

Una parte sustancial del debate reciente ha derivado hacia la necesidad de generar una "compensación" económica frente a la moratoria de extracción del petróleo. El convertir esa prioridad en una condición indispensable para llevar adelante la Iniciativa, si bien tiene varios aspectos positivos, tiene también otros negativos. Entre los positivos es clave reconocer que podría asegurar ingresos a las arcas del Estado, que pueden ser muy útiles en mantener políticas sociales o ambientales, y serviría para desarticular la oposición de quienes entienden que la medida es una renuncia a la rentabilidad prevista por la explotación del crudo.

Pero existen aspectos negativos, en tanto esa “compensación” no necesariamente asegura ni está directamente vinculada con las comunidades locales, o con una protección o restauración ambiental en las áreas deterioradas, o que han perdido capacidad de sustentación de las poblaciones. En otras palabras, se pueden sumar enormes cantidades de dinero desde el campo internacional, sin que eso resulte en políticas ambientales y sociales certeras y efectivas en la región amazónica. El argumento pro “compensación” depende de la confianza que disfrute el gobierno en cumplir con sus compromisos de desarrollo frente a los sectores más vulnerables del país. Dejar todo reducido a la posible “compensación” económica internacional implica olvidar las demás razones que sustentan la propuesta. Es como si se decidiera mantener en suspenso otros mandatos constitucionales hasta no obtener una cierta compensación o ayuda internacional. De la misma manera, esa postura debilita al propio Estado, en tanto su capacidad de acción pasa a depender de recibir fondos internacionales. Sin embargo, el argumento pro “compensación” recaerá bien tanto nacional como internacionalmente, toda vez que el país sufre altísimas incidencias de pobreza. Muchos compartirán la filosofía que la ética tiene que reflejar el estado en que se encuentra el sistema. Por lo tanto, la conservación del ITT es importante en sí misma, independientemente de los humores y disponibilidad de pago de la comunidad internacional. La demanda de compensación económica internacional no puede ser usada como excusa para la inacción, sino que debe ser vista como una oportunidad para la acción nacional e internacional. La falta de cumplimiento de cooperación internacional en la capitalización de un desarrollo sostenible en el Ecuador tiene que entrar como un débito conmensurable en la deuda ecológica. Por ejemplo, se pueden medir cuánta inversión internacional es prescindida por la conservación de Yasuní y cuantas emisiones de CO2 serán evitadas -la suma de dichos valores es el piso para el cálculo del rubro de la deuda.

Siguiendo con este razonamiento, si la compensación económica 
internacional es algo así como un coadyuvante, pero no una meta en sí misma, la responsabilidad última de la gestión política está en manos del Estado ecuatoriano, y no en manos de la comunidad internacional. El gobierno no puede anular la protección del área invocando que la comunidad internacional es mala, insensible, o tacaña al negarle el apoyo financiero, sino que debería seguir adelante a pesar de ello. Esto pasa por llevar a los escenarios políticos los temas centrales de la desigualdad, de la justicia ambiental y climática, planteados desde una posición que además de la crítica, encierra una propuesta.

Este análisis no implica que los autores nieguen la importancia del apoyo financiero internacional, sino que apunta a dejar en claro que éste debe responder a la lógica y las propuestas de la preservación de la región del Yasuní como una política pública nacional que coincide con una política internacional de reducir las emisiones de CO2. Por lo tanto, las negociaciones internacionales, y los instrumentos para aprovechar las oportunidades de apoyo financiero, se deben ajustar a ese mandato político, y no a la inversa - donde las medidas nacionales terminan siendo funcionales y dependientes de los fondos de los países ricos.

\section{c) Cambio climático y mercado de carbono}

Entre las posibles opciones económicas para lograr fondos se ha discutido apelar a los llamados "mercados de carbono" en el marco de las medidas contra el cambio climático. Estos están basados en lograr reducciones en la emisión de gases contaminantes globales, que se originan en emprendimientos en los países industrializados, a partir de “comprar" ciertas medidas compensatorias en los países del sur. Por ejemplo, para anular el impacto de los gases que emitirá una nueva fábrica en Holanda, se financian medidas de reforestación en un país del sur, las que debería cubrir una superficie que permitiera absorber una cantidad equivalente de CO2 a los producidos por el emprendimiento holandés. Esas reducciones son utilizadas por los países industrializados para alcanzar sus metas en el Protocolo de Kyoto. Este tipo de medidas se han amparado en los llamados "mecanismos de desarrollo limpio" (MDL) del Protocolo de Kyoto (un instrumento de la Convención Marco en Cambio Climático), y en un mercado paralelo donde se venden y compran "bonos” de aquellas acciones que supuestamente fijan gases de carbono en el sur, tales como protección de bosques nativos, reforestación, etc.

Se podría postular que al dejar el petróleo en tierra, se evitaría la emisión de una cierta cantidad de gases con efecto invernadero, y por lo tanto Ecuador podría reclamar una compensación por ello. Sin embargo, esto no está contemplado en los mecanismos existentes dentro de las negociaciones de Kyoto. Por otro lado, el volumen de CO2 fijado depende de la superficie del bosque, y por lo tanto en el caso de Yasuní, éste aporte sería limitado desde esta perspectiva, puesto que no incorpora el petróleo que se dejaría de quemar. 
En el caso de avanzar en este camino se deben tener en cuenta varios problemas propios de las negociaciones para fijar el CO2. Su efectividad es motivo de controversias ya que no hay evidencias certeras de un aporte sustantivo en generar una reducción en las emisiones, en tanto no está claro cuánto CO2 se estará reduciendo, si es que esto sucede (véase, por ejemplo, Schneider, 2007; Ward y Victor, 2008). Además, hay posibilidades de que se produzcan efectos perversos ("leakages", en la terminología del Protocolo de Kyoto, o efectos de "segundo mejor" en la microeconomía matemática). Por ejemplo, rozar y quemar un bosque primario para luego sembrar eucalipto no fue contemplado originalmente en este protocolo. Este "mercado de carbono", construido como espacio para procesar una salida a los conflictos del cambio climático, es realmente un nuevo negocio del desastre climático, ya que hay empresas contaminantes y los intermediarios están haciendo millonarias ganancias, sin que se conozcan avances sustantivos en esta materia.

El mercado de carbono voluntario es aún más peligroso que el del Protocolo de Kyoto, que está de cierta manera regulado en tanto fija una cuota a un país y éste a sus empresas. Pero el mercado voluntario está creciendo sin ningún tipo de regulación, lo que disminuye las opciones que buscan establecer límites de emisión para los diferentes países. Es decir anula el desarrollo de adecuadas políticas ambientales, cada vez más indispensables para enfrentar los crecientes problemas ecológicos.

El marco internacional actual incluye una condicionalidad que limita sustancialmente su aplicación para el caso Yasuní. En efecto, los “mercados de carbono" son para contrabalancear las emisiones que se reducen en países industrializados y de economías en transición, pero no se aplican sobre el origen del combustible que se quema en esas naciones. Una vez que se extrae el petróleo desde Ecuador, éste puede ser consumido en cualquier país del mundo, y por lo tanto no se puede asegurar que reducirá las emisiones en un país o en otro. Los mecanismos actuales se basan en emprendimientos específicos, tales como fábricas o rellenos sanitarios. No existe una contabilidad global sobre el uso de combustibles, ni se están negociando limitaciones sobre éstos como medio de combatir el cambio climático.

Establecidas estas limitaciones, también es cierto que las negociaciones internacionales, y en especial sobre cambio climático, ofrecen algunas oportunidades, las que son discutidas más abajo.

\section{Los caminos posibles en la instrumentación de la iniciativa}

Tal como se ha explorado en el presente documento, queda en claro que la instrumentación de la Iniciativa ITT requiere por un lado, posicionarla nítidamente como una política pública, y por el otro lado, identificar los medios e instrumentos de viabilidad. En los caminos de esa puesta en mar- 
cha de esta Iniciativa existen muchas opciones, y esta diversidad no es un problema en sí mismo, ya que permite evitar depender de un único pilar de sustentación. El reto está en que esos instrumentos sean funcionales entre sí, complementándose mutuamente y que si uno de ellos falla, los demás permitirán el avance de la Iniciativa. Seguidamente se presenta un resumen de los principales medios de instrumentación. Algunos de ellos, en especial los económicos, son comentados con más detalle en las secciones siguientes.

\section{Principales medios de instrumentación:}

\section{a) Normativos}

A partir de la nueva Constitución queda claro que la preservación del área de Yasuní responde a un mandato constitucional, que se debe expresar como una política pública nacional. Esto implica armonizar la vieja legislación a la nueva Constitución, y que los vacíos legales que se identifiquen, deben ser llenados. La próxima ley orgánica en materia ambiental debe permitir y alentar la preservación del Yasuní, y no impedirla.

\section{b) Apoyos financieros}

Entendido como mecanismos coadyuvantes, que fortalecen la propuesta, pero que están condicionados por el mandato político. En este campo existen varias opciones, también complementarias entre ellas. Podemos citar las siguientes:

- Creación de un fondo estatal, específicamente orientado a la protección del área, y que opera de la misma manera bajo la cual se constituyen las partidas presupuestarias estatales para otras políticas públicas como educación o salud.

- Fondos extraordinarios, bajo la premisa de aliviar o contrabalancear los recursos no devengados por la explotación comercial de los campos ITT.

- Fondos obtenidos por la cooperación internacional bilateral y multilateral, y por otros donantes (personas, empresas, etc.).

\section{c) Nuevas posturas en la negociación internacional}

Es un capítulo indispensable, en tanto el fortalecimiento de la propuesta, y la búsqueda de recursos financieros, requerirá de apoyos internacionales. Este aspecto se discute con más detalle más abajo, pero se puede adelantar que requiere acciones en el ámbito del Tratado de Cooperación Amazónica (donde Ecuador es miembro), en el espacio regional sudamericano, y a nivel global en las discusiones sobre cambio climático. Estos deben apuntar a efectivizar el apoyo financiero a la moratoria en base a una contabilidad global, y éste punto actualmente no se encuentra en discusión para el sector energético. Este paso requiere coordinaciones 
con los demás países latinoamericanos, y una negociación delicada en el seno del G77+China.

\section{La estructura y opciones de financiamiento}

Con esta propuesta lo que se busca es un acuerdo político para constituir uno o más fondos, que permitan cumplir con el objetivo planteado. Las posibilidades que aquí se presentan no agotan las opciones existentes, algunas de las cuales podrían incluso recién aparecer como resultado del debate planteado.

\section{a) Administración}

El Estado negociará y administrará los fondos involucrados en la Iniciativa ITT para mantener el crudo en el subsuelo. No se traspasarán las responsabilidades de la conservación a entidades privadas nacionales o extranjeras, ni la formulación de políticas sobre conservación, ni tampoco la administración de las áreas protegidas. Debe quedar establecido desde el principio que la Iniciativa ITT es una cuestión en primer lugar ecuatoriana, que busca proteger a los pueblos libres en aislamiento voluntario y a la biodiversidad de la zona. Sin embargo, simultáneamente es una cuestión de trascendencia internacional, vista desde la lógica de la corresponsabilidad que tiene, sobre todo, los países ricos, causantes directos de la mayor cantidad de desequilibrios ambientales.

\section{b) Fuentes de financiamiento}

El fondo se puede nutrir desde varias fuentes, y entre ellas deseamos mencionar las siguientes:

1. Fondos externos al Ecuador:

- Aportes del sistema de Naciones Unidas y los bancos multilaterales de desarrollo. Por ejemplo, GEF.

- Aportes de la cooperación bilateral, o multilateral.

Esto incluye los fondos que puedan aportar gobiernos (tales como es la intención de Alemania), o por grupos de países.

- Aportes de personas, organizaciones ciudadanas, empresas, etc., actuando a título propio.

- Fondos que pudieran crearse bajo mecanismos internacionales en el marco del próximo protocolo sobre cambio climático que debe reemplazar al de Kyoto, orientados a evitar la emisión de CO2. Este fondo podría ser el más grande ya que incluiría tanto los yacimientos no aprovechados como los bosques preservados.

2. Fondos provenientes de un sistema de imposición global

- Ecoimpuesto

3. Fondos originados en Ecuador

- Reestructuración de deuda externa a través de la emisión de un 
bono especial

- Emisión de "sucres” con respaldo del crudo del ITT

También se pueden generar complementaciones entre los mecanismos. Por ejemplo, los ciudadanos y las ciudadanas de los países más ricos, que aporten a la conformación de este Fondo ITT, podrían obtener un descuento fiscal del monto de sus impuestos a pagar en su país de origen como aliciente al aporte voluntario que están realizando con miras de reducir los problemas derivados del calentamiento global.

El punto que se desea subrayar en que existen diferentes opciones a las cuáles se puede apelar para nutrir un fondo que sustente económicamente la Iniciativa ITT, y que éstas no son necesariamente excluyentes entre sí, sino que son complementarias.

\section{c) Mecanismo y garantías}

El Estado ecuatoriano emitiría certificados no negociables (Certificados de Garantía) por renunciar al crudo en el subsuelo de la Reserva Yasuní, donde sin duda se deben contemplar garantías para reclamar en caso que el Estado no cumpliera con sus compromisos (es decir si el crudo es extraído). Para poder manejar los recursos se podría constituir un fondo de fideicomiso, temporario hasta que se presupuesten inversiones nacionales que fomenten el desarrollo sostenible.

En este punto hay que dejar sentada la necesidad de asegurar a todas las personas, naturales o jurídicas, que aporten para la constitución de este Fondo ITT, el adecuado uso de los recursos acumulados. Todos los aportantes deben tener la certeza de recuperar su dinero si el Estado ecuatoriano incumple su compromiso. En este caso deberían aplicarse las medidas de sanción acordadas dentro de la constitución de las garantías.

En el caso de que en el futuro algún gobierno ecuatoriano extraiga el crudo, éste, en primera instancia, debería ser comercializado para financiar los aportes recibidos. Los pagos por no haber emitido el CO2 fluirían a través de los gobiernos futuros y podrían ser un incentivo fuerte para respetar la garantía. La administración también debe contener espacios de participación de representantes de las comunidades amazónicas, sobre todo aquellos afectados por la actividad petrolera, y por delegados de las organizaciones ciudadanas.

El uso de los fondos debería, en primer lugar asegurar la protección ambiental y social de la zona de Yasuní; en segundo lugar, como prioridad, apoyar y promover emprendimientos sostenibles en las demás zonas amazónicas, desde tareas de conservación a las acciones de restauración ambiental debida a los impactos de la explotación petrolera. Este fondo no puede repetir la historia de críticas, ineficiencia y opacidad del FEIREP (Fondo de Estabilización, Inversión Social y Producción, y Reducción del Endeudamiento), que terminó atrapado en la especulación financiera y que 
estaba orientado casi exclusivamente a sostener el servicio de la deuda pública externa e interna (Falconí y Ponce, 2005).

\section{d) Dotación del fondo}

El volumen de recursos que debería manejarse con el fondo (o los fondos) merece una serie de comentarios. Es posible distinguir al menos tres escenarios posibles:

- Monto definido por el dinero necesario para ejecutar las medidas de protección ambiental y salvaguardia de las comunidades locales.

- El volumen que correspondería a equilibrar la renta que el Estado no obtendría al dejar de explotar el crudo en el ITT. Esta opción será fundamentada por algunos como una forma de "compensación".

- Finalmente, incluso se podría pensar en un fondo amplio definido por el dinero necesario para capitalizar el país con infraestructura más amigable al ambiente, para pasar por el cuello de botella hasta que se pueda calificar como un país de la primera categoría en el Î́ndice de desarrollo Humano del PNUD.

La primera opción es bastante sencilla, ya que involucra asegurar los fondos para, por ejemplo, mantener el área protegidas, sus guardaparques, etc., y cubrir las necesidades de las comunidades locales.

La segunda opción es mucho más compleja. Por un lado, se puede discutir cuál es la proporción de fondos reclamados: ¿ la mitad del ingreso esperado por el Estado? ¿Más del 50\%? ¿O una cifra menor? Asimismo, ¿cuáles son los criterios para reclamar un $50 \%$ de los ingresos esperados, y no por ejemplo, el $75 \%$ o el $25 \%$ ?

La tercera opción es la más realista por sostener la garantía que el Yasuní jamás será explotado por los recursos naturales allá presentes.

Por otro lado, el cálculo del valor de referencia del ingreso esperado es por demás complejo, y puede arrojar resultados distintos. En efecto, es necesario determinar si se considerarán únicamente las rentas por los potenciales ingresos debido a la comercialización; la forma en que se consideran (o no) las inversiones necesarias para la extracción del crudo y la construcción de infraestructura (tales como una planta de generación de electricidad con residuos del crudo pesado, en la propia Amazonía); e incluso el precio de referencia para el petróleo. No olvidemos que la caída del precio del crudo en los mercados internacionales estaría determinando una reducción desde 11.000 millones de dólares en los ingresos esperados (unos 847 millones anuales), a 1.290 millones de dólares (unos 99 millones anuales), calculado para un precio del barril de crudo WTI (mucho menos pesado que el del ITT) de 40,9 dólares (al 22 de diciembre de 2008). Este aspecto también contribuye a fundamentar las limitaciones de condicionar la iniciativa a una mera compensación económica calculada en base a la renta esperada. Es que esa evaluación se movería al vaivén de los precios 
internacionales del crudo, lo que podría devenir en un ejercicio propio de actividades especulativas.

Es oportuno presentar algunos comentarios y profundizaciones sobre algunas de las opciones de financiamiento indicadas arriba.

\section{Reestructuración de deuda externa a través de la emisión de un bono especial}

Se trataría de un mecanismo de reestructuración de la deuda externa para convertirla en bono especial: se suspende su esencia como papel de deuda mientras el Estado ecuatoriano mantiene el crudo en tierra, y como mecanismo de seguridad, en caso de que se llegare a explotar ese petróleo, el papel se transformaría nuevamente en deuda clásica. Esta propuesta sería una herramienta para una negociación política a nivel internacional, por ejemplo rescatando la decisión que resultó de la auditoria de la deuda, de no pagar una deuda ilegítima y de reconocer el resto.

Este podría ser un mecanismo bastante ágil y masivo para capitalizar el Fondo ITT, en la medida que se liberarían recursos del Presupuesto General del Estado, antes destinados a servir la deuda, y que ahora se utilizarán para incrementar el monto de recursos que viabilicen la propuesta. Los términos de la reestructuración deben ser considerados con mucho cuidado. Con el canje de deuda, por ejemplo, se aceptaría la legitimidad del tramo de deuda externa que se vaya a reestructurar. Recuérdese que la emisión de todos los Bonos Global tiene vicios de diverso tipo, que han llevado a considerarlos ilegítimos, por lo que su reestructuración simplemente legitimaría este tipo de deuda.

Si el mecanismo prospera, podría dar lugar a acuerdos más amplios y ambiciosos. Como complemento de la Iniciativa ITT se podría suscribir un acuerdo con los acreedores bilaterales y multilaterales de Ecuador con el fin de suspender el servicio de todas las deudas bilaterales y multilaterales, con el único compromiso de dar paso a una moratoria petrolera en todo el sur del país, más allá del ITT.

\section{Ecoimpuesto}

En este caso, un mecanismo alternativo se basaría en la propuesta del presidente Rafael Correa elevada a los países miembros de la Organización de Países Exportadores de Petróleo (OPEP), para imponer un impuesto sobre cada barril exportado. Con los recursos obtenidos se capitalizaría un fondo para financiar una reconversión energética en dichos países y para salvaguardar de la explotación petrolera zonas ecológicamente frágiles en el planeta, y entre ellos perfectamente entraría la protección del Yasuní. Este impuesto ha sido llamado Impuesto Daly-Correa, reconociendo a sus promotores: Herman Daly por su aporte intelectual y Correa por su iniciativa política. 
En la misma línea, el ministro del Ambiente de Brasil, Carlos Minc, propuso en abril de 2009, ante los países miembros del G-8 (Grupo de los Ocho), un impuesto del $10 \%$ sobre los beneficios de la industria petrolera para alimentar los fondos que los países en desarrollo emplean para luchar contra el cambio climático. Este impuesto establecería un costo adicional para los grandes países importadores del petróleo, principales responsables del cambio climático. Se observa que si no fuera por la cartelización del petróleo en la década de 1960 y la correspondiente disminución de la demanda, los cambios climáticos podrían haberse acelerado. De forma inesperada e irónica, la OPEP ha servido a los fines ecológicos. El fondo se manejaría en forma soberana por los miembros integrantes de la OPEP.

Con estos recursos se podrían desplegar proyectos de apoyo a los países empobrecidos que carecen de crudo, en el marco de una agenda de solidaridad energética global. Los aportes que recibiera Ecuador por ese impuesto podrían dirigirse directamente a capitalizar la Iniciativa ITT. Sin embargo, esta ventaja podría diluirse, puesto que la OPEP fija el precio de petróleo en una zona elástica de la demanda global de petróleo, que haría que, a la postre, gran parte del impuesto recaiga sobre los mismos países exportadores, dificultando así la aceptación del mismo. Por lo tanto, la viabilidad de esta opción no sólo compete a los países exportadores, sino también a los importadores, particularmente a los grandes (como EEUU, Japón y Europa), los que deberían aceptar que una parte del precio final del crudo se destine a financiar fondos como el de la Iniciativa ITT.

\section{Emisión de "sucres" con respaldo del ITT}

En América Latina, en el marco de la conformación del Banco del Sur y un Fondo de Estabilización del Sur, se ha pasado a discutir la creación de un Sistema Unitario de Compensación Regional (SUCRE), que facilite los flujos comerciales regionales y que aliente una progresiva desdolarización de las relaciones comerciales y financieras interregionales. Esta Iniciativa podría ser la antesala de un sistema monetario y financiero regional, la que debería ser complementada con su propio código financiero. La Iniciativa ITT podría ligarse a este sistema como forma de respaldo, donde en el caso de Ecuador éste estaría representado por crudo existente en el subsuelo del Yasuní. De esta manera, esas reservas desempeñan un papel similar al que tuvo el oro en el pasado, como respaldo de las monedas nacionales. En este caso, es importante demostrar que esto no es titularización de reservas, pues se basa en la idea de no explotarlas.

\section{Las negociaciones internacionales}

Muchas de las diferentes facetas que puede asumir la Iniciativa ITT exigen un fuerte protagonismo del Ecuador en las negociaciones internacionales. A nuestro juicio, la propuesta requiere ese componente internacional en forma indispensable. Por lo tanto es oportuno repasar algunos de esos aspectos. 
Esta iniciativa, en tanto apuesta a proteger un ecosistema amazónico, debería buscar el apoyo y la coordinación con los demás países signatarios del Tratado de Cooperación Amazónica. Ecuador, junto a los demás países amazónicos integra la organización de dicho tratado (OTCA, con sede en Brasilia), el que es uno de los pocos acuerdos regionales con un mandato específico para la protección de la biodiversidad y los recursos naturales de la cuenca. En ese terreno es importante revisar el caso del PPG7 (Programa Piloto para la Protección de los Bosques Tropicales), entre el gobierno de Brasil y los países industrializados, en ese entonces agrupados en el G-7 (Grupo de los Siete). El programa, iniciado en 1992, es muy ambicioso, y cuenta con apoyos de varios países (en especial Alemania) y del Banco Mundial; constituye un ejemplo de coordinación internacional en materia de protección ambiental, sobre un ecosistema clave para Brasil pero también a escala global (véase, por ejemplo, Andrade Abdala, 2008). A partir de este caso se pueden explorar varias opciones para el ITT, tales como establecer un mecanismo similar específico para esa región, un programa análogo para toda la Amazonía ecuatoriana, etc.

En el espacio andino, el compromiso de 2002 sobre conservación de la biodiversidad en la Comunidad Andina constituye una base sustancial para negociar apoyos y coordinaciones. A nivel continental, sería conveniente presentar la iniciativa en la Unión de Naciones Suramericanas (UNASUR), en tanto es un foro político donde en particular se han tratado los temas energéticos. Está claro que en esta tarea existirán aliados más cercanos al mandato de protección de los recursos naturales, mientras que en otros casos los intereses de otros países exportadores de petróleo pueden divergir al privilegiar la comercialización del crudo, o debido a que pueden promocionar que sus empresas petroleras naciones ingresen al área de Yasuní. Estamos conscientes de esas disparidades y tensiones, pero más allá de ellas el punto que se desea subrayar es que esta propuesta tendrá mucho más posibilidades de fructificar si logra apoyos y alientos desde los países vecinos.

A nivel global, el primer escenario a considerar son las negociaciones en la Convención Marco del Cambio Climático. En este momento tienen lugar febriles negociaciones para avanzar hacia una reformulación del Protocolo de Kyoto. Como se discutió arriba, los actuales formatos contemplados en esos acuerdos no son fácilmente utilizables por una iniciativa como la moratoria en el ITT, debido a que los compromisos de reducción están específicamente anclados en los países industrializados y en transición, y a la ausencia de un procedimiento de evaluación y reconocimiento a la reducción de emisiones originadas por suspender la venta de petróleo.

Si bien estos y otros aspectos son una dificultad, también es cierto que el humor político en esas negociaciones ha cambiado, y existen crecientes presiones por compromisos más ambiciosos. Asimismo, hay muchos mecanismos alternativos que comienzan a ser discutidos. Con algunas limitaciones conceptuales, se ha iniciado el debate sobre un acuerdo mundial para reducir la deforestación como fuente de emisiones globales, y su línea de fundamentación tendría algunas similitudes con la Iniciativa ITT: 
permitiría contabilizar el aporte de gases que no son emitidos al no explotarse ese petróleo. Sea este u otro camino, es importante que se tomen decisiones concretas, y que Ecuador comienza a elevar propuestas formales.

En cualquiera de estos casos entendemos que es oportuno un cambio en el tono y sentido del posicionamiento negociador del país. No es aconsejable presentar una propuesta de este tipo insistiendo en el reclamo de compensaciones como eje central, o en el "sacrificio" que realizaría el país. Es que esa postura es contraproducente, ya que se parte por subrayar la importancia ambiental del área y la relevancia de proteger los grupos indígenas, y por lo tanto muchos se preguntan porqué es necesario compensar a un país que ya ha reconocido la relevancia y urgencia de esa tarea. En otras palabras, no es la comunidad internacional la que le pide un esfuerzo adicional o extraordinario a Ecuador, sino que éste ha reconocido, en sus decisiones y en su normativa, la enorme importancia de la región de Yasuní. Asimismo, esa postura refuerza la creciente imagen que los países del sur sólo están dispuestos a medidas contra el cambio climático en la medida que las naciones industrializadas les paguen por ello. Por lo tanto, el país enfrenta la oportunidad de ejercer un liderazgo en las negociaciones internacionales, pero para tener éxito en esa tarea debería abandonar esos viejos discursos y esas viejas prácticas.

Nos encontramos frente a un momento donde es posible promover y contribuir a generar nuevos compromisos y acuerdos, esperemos que vinculantes, de coerción mutua, para cumplir con las obligaciones internacionales. Esto requiere un papel mucho más activo y protagónico de la diplomacia ecuatoriana, como por ejemplo, elaborando marcos conceptuales, escenarios de aplicación, e intervenir con energía y persistencia en las negociaciones internacionales sobre cambio climático. En este punto el gobierno ecuatoriano debe redoblar sus esfuerzos, y la Cancillería debería liderar la presentación de la Iniciativa ITT. En particular en negociaciones de la Cumbre de Cambio Climático, Ecuador podría promover un enfoque global y metas nacionales para avanzar hacia la sustentabilidad, donde se consigan reducciones sustanciales en las emisiones de gases.

Se debe apuntar a países “neutrales” en la emisión de carbono, y de esta manera moverse hacia mejores indicadores de desarrollo. La discusión internacional de la propuesta puede inspirar a otros países, también serviría de ejemplo para otros países, en aspectos como tomar decisiones soberanas para superar la dependencia, crear condiciones para que se financien propuestas similares, y recuperar y potenciar los principios de responsabilidades comunes pero diferenciadas.

\section{A manera de conclusión}

El presente documento apunta a revitalizar y promover una discusión más profunda sobre la Iniciativa ITT para mantener en tierra, sin explotar, el petróleo en la zona del Parque Nacional Yasuní. Entendemos que 
esta iniciativa es viable, y que debe ser enfocada como una política pública. La relevancia social y ambiental del área ha sido argumentada desde los más diversos frentes, y la legislación nacional, y en particular la nueva Constitución, convierten a la protección de esa área en un imperativo político nacional. Por lo tanto la discusión es cómo llevar ese mandato a la práctica.

En el plano nacional, entendemos que la Iniciativa ITT es parte del recorrido hacia un nuevo desarrollo basado en el concepto del Buen Vivir. Pero la iniciativa también es muy importante a escala regional, en tanto Ecuador es un país amazónico, y a escala global, por sus efectos sobre el cambio climático y el acervo planetario en biodiversidad. Los aspectos económicos de la Iniciativa son analizados desde variadas ópticas. Se destacan algunas de las tensiones que encierra este debate en áreas como la valorización económica. Reconocemos que la obtención de fondos permitiría fortalecer las posibilidades de instrumentar la iniciativa, pero en tanto ésta es concebida como una política pública, no pueden usarse las cuestiones financieras como una excusa para la inacción.

La importancia de preservar el área ha sido establecida incluso por las propias autoridades gubernamentales, y en más de una ocasión. Por lo tanto el reclamo de la compensación internacional tiene que ser entendido más como una propuesta enmarcada en las políticas internacionales que buscan la justicia climática, que como una condición para proteger el área, pues el Estado reconoce como prioritaria la protección y conservación del área, objetivo previsto también en la propia legislación ecuatoriana. De todas formas es importante señalar que el Ecuador reconoce la urgencia de impulsar acciones internacionales tendientes en enfrentar los problemas globales, creando las condiciones prácticas para ello y enmarcándose en las responsabilidades comunes pero diferenciadas.

Concordamos en que los mayores esfuerzos deben ser colocados en visualizar varias opciones políticas y económicas para constituir tanto uno o más fondos, de distintos orígenes, y complementarios entre sí, como acuerdos internacionales que contribuyan al objetivo de encaminar al Ecuador al Sumak Kawsai y hacia una economía post petrolera. Por lo tanto se trata de impulsar acciones concretas para abrir las puertas a más de una opciones de respaldo político, internacional e incluso de financiamiento. En estas tareas entendemos que es muy importante un papel activo de Ecuador en las negociaciones internacionales, tanto con las naciones vecinas de América Latina, como en los debates globales sobre cambio climático. Existen experiencias regionales que deben ser tenidas en cuenta, la coordinación con otros países es necesaria, y por sobre todas las cosas se debe asumir un papel de liderazgo en las negociaciones regionales y globales. 


\section{Bibliografía}

Acosta, Alberto (2009), La maldición de la abundancia. ¿Del petróleo a la minería a gran escala?, Quito (en prensa).

Andrade Abdala, F. de. (2008), "Governança global sobre florestas: estudo exploratório sobre o caso do programa piloto para proteção das florestas tropicais do Brasil (1992-2006)" en Ajedrez ambiental. Manejo de recursos natuales, comunidades, conflictos y cooperación, J.S. Weiss y T. Bustamante (eds.), FLACSO y Ministerio de Cultura de Ecuador, Quito.

Berinstain, Carlos Martín, Páez Rovira, Fernández, Itziar (2009), Las palabras de la selva - Estudio psicosocial del impacto de las explotaciones petroleras de texaco en las comunidades amazónicas del Ecuador. HEGOA, Bilbao. Disponible también en http://pdf2.hegoa.efaber.net/entry/content/ 442/Las_palabras_de_la_selva.pdf

Comunidad Andina (2002), Estrategia regional de biodiversidad para los países del trópico andino, Resolución 523, Consejo Andino de Relaciones Exteriores, Lima.

Falconí B., F. (2004), "Los pasivos de la industria petrolera. A propósito del juicio a la Texaco" en Petróleo y desarrollo sostenible en Ecuador. 2. Las apuestas, G. Fontaine (ed.), FLACSO, Quito.

Falconí B., F. y J. Ponce J. (2005), "¿Influyen los precios del petróleo en el alza de los Global 12? Una reflexión de coyuntura sobre el endeudamiento externo ecuatoriano" en Iconos $N^{\circ}$ 23: 9-15, FLACSO Quito.

Fontaine, G. (2007), Entre ecologismo utópico y nacionalismo pragmático: el proyecto Ishpingo, Tambococha y Tiputini (ITT) y la gobernanza energética en el Ecuador. Observatorio Socioambiental, FLACSO, Documento de Trabajo No 1, diciembre 2007, Quito.

Fontaine, G. y Narváez, I. (2007), "Problemas de la gobernanza ambiental en el Ecuador" en: Yasuní en el siglo XXI. El estado ecuatoriano y la conservación de la Amazonia, G. Fontaine e I. Narváez (coords.), FLACSO, Quito.

GeoAmazonia (2008), Perspectivas del Medio Ambiente en la Amazonia. GeoAmazonia. OTCA, PNUMA y Universidad del Pacífico, Lima.

Martínez, Esperanza (2009), "Yasuní: dejar el crudo en tierra, un reto a la coherencia" en Revista La Tendencia No 9, ILDIS, Quito, marzo-abril.

Narváez, I. (2007), "La política ambiental del Estado: ¿Hacia el colapso del modelo de conservación?" en Yasuní en el siglo XXI. El Estado ecuatoriano y la conservación de la Amazonia, G. Fontaine e I. Narváez, (coords.). FLACSO, Quito. 
Idem (2009), Petróleo y poder: el colapso de un lugar singular, Yasuní. FLACSO - GTZ, Quito.

Schneider, L. (2007), Is the CDM fulfilling its environmental and sustainable development objectives? An evaluation of the CDM and options for improvement. Report prepared for WWF, Institute for Applied Ecology, Berlin, 5 November 2007.

Vogel, Joseph (2009),. The Economics of the Yasuni ITT Initiative (mimeo).

Wara, M.W. y D.G. Victor (2008), A realistic policy on international carbon offsets. Program on Energy and Sustainable Development, Stanford University, Working Paper \#74, abril 2008. 